CIENCIA Y SOCIEDAD

Volumen IX, N!úmero 1

Enero-Abril 1984

ARTICULOS

EL SISTEMA AGRICOLA DOMINICANO

JULIO A. CROSS BERAS

EL SISTEMA AGRICOLA

Desde los tiempos coloniales hasta el día de hoy, los dominicanos, que consideran viven en un país agrícola, han intentado crear un sistema agrícola, ensayando las más diversas modalidades, desde la plantación azucarera basada en la esclavitud, hasta la reforma agra$\mathrm{ria}$, pasando por la pequeña finca familiar orientada al mercado exter no y la gran plantación azucarera de corte industrial, ensayando en $\mathrm{e}^{\bar{T}}$ interim varios cultivos, desde el jengibre hasta el sorgo.

En este artículo pretendemos sugerir una respuesta a la pregunta sobre la naturaleza agrícola del país. Una respuesta definitiva requiere un examen histórico exhaustivo, que traspasa los linderos es trictos de la economía, para convertirse en una extensa investigación sobre la existencia misma del país. Hunter (1974:3), refiriéndose es pecíficamente al cambio rural, considera que "estudiar el desarrollo rural es inseparable de otros elementos no económicos, (tales como) la historia, las creencias, las instituciones, la educación, la política, la administración, las ambiciones y los ideales". En términos más simples, el curso histórico de la sociedad rural y los cambios operados en su estructura y en su cultura. Esta tarea queda pendiente para el día que se escriba una historia económica de la República Dominicana. 
Mientras tanto, este artículo se limita a ser una sugerencia sobre algunos tópicos que deberían considerarse. Un buen arma metodológica, dentro de esta perspectiva para estudiar una sociedad, es el concepto de sistema. La clave en esta línea de pensamiento es la forma en que se organiza la estructura productiva, como señala Thorner (1975:202) cuando dice que "es esencial definir la economía agrí cola como un sistema de producción y distinguir éste de otros sistemas históricos".

Cuando hablamos de sociedad agrícola, tenemos en mente, antes que nada, a partir del concepto de sistema, una unidad que engloba y vincula diversos tipos de actividades de acuerdo a un principio bási co unificador (Thorner, 1975). En otras palabras, a partir de un pun to de vista macrosociológico, en el caso dominicano, la fuerza organizadora de todo el sistema es el Estado. Dentro de este esquema, el sector propiamente agrícola de la sociedad, que en un sistema agrario es el más importante y definitorio del sistema social global, se debe considerar como "orientado hacia la nación", como sugiere Wolf (1975:51) cuando dice:

comunidades que forman parte de una sociedad compleja no pueden ya verse como sistemas autocontenidos e integrados en su propio derecho. Es más apropiado verlos como la terminal local de una red de grupos de relaciones que se extienden a través de niveles intermedios desde el nivel comunal al de la nación.

Estas relaciones, sin embargo, no pueden verse como monotóni cas, si se utiliza el concepto de sistema. Tambiên hay que presta atención al grado de integración entre los diversos grupos a nivel comunal y en los niveles intermedios. Foster (1967:13) describe esas relaciones, al decir que "a través de redes sociales, religiosas y económicas, mantienen contactos estrechos con gentes en aldeas vecinas, de tal manera que cada comunidad rural es de hecho parte de una sociedad rural más amplia'".

Lo que pretendemos es elaborar a grandes rasgos un modelo, no una clasificación, del sistema agrícola. La metodología a seguír es construir un modelo teórico y comparar éste con la realidad. Feudalismo, capitalismo, socialismo, más que tipos de clasificación, son modelos de sociedades históricas. El ruso Alexander Vasilevich Chay nov fue muy probablemente uno de los primeros en proponer esta idea. Chaynov (Kerblay, 1975:151) "intentó mostrar que a las categorías distintivas y modos de producción que Marx reconoció... debe añadirse otra: la economia agricola". Estas ideas, que se contraponían a la politica oficial de colectivización en Rusia, le valió la cárcel a su autor, pero suprincipal contribución ha permanecido, que consiste 
en "aportar una teoría del comportamiento campesino a nivel de finca individual y familiar $y$, en segundo lugar, mostrar que a nivel nacional la economía agrícola debe ser tratada como un sistema económico en su propio derecho'" (Kerblay, 1975:151).

Al caracterizar el sistema agrícola, hay que tomar en cuenta las diversas modalidades que puede tomar éste. Así, se pueden considerar dos formas sociales de producción agrícola en época contemporánea, "dos instituciones o formas principales de la producción. Una es la familia y la otra la gran empresa agrícola, que hoy se asemeja a la empresa industrial, basada en una unidad de trabajadores que no consti tuyen una familia" (Galeski, 1975:115). Ambas pueden ser considerāa das como extremos de un continuo de desarrollo, aunque en la realidad coexisten en una etapa transicional. De hecho, la tendencia moderna es la conversión del sistema familiar de producción en empresa agríco la explotada siguiendo criterios racionales modernos de administración y producción para el gran mercado externo a la comunidad rural, mientras en la misma medida tiende a disminuir en importancia el autoconsumo con la integración del productor a una economía de mercado.

El propósito principal de la agricultura "puede ser definido co mo sigue: suplir a la humanidad con alimentos y con aquellas materias primas que son de origen animal o vegetal"1 (Dumont, 1975:141). En el cumplimiento de este fin, y producto de la propia dínámica que hace que ésta utilice el medio ambiente eficientemente para responder a las demandas del sistema, la "agricultura ameliora los extremos del clima; con irrigación el agricultor lucha contra la aridez; cobija sus animales y protege sus cultivos mercadeables con cercas e invernaderos contra el viento y el frío. Sobre todo, la agricultura modifica el suelo" (Dumont, 1975:141). En consecuencia, "la etapa de desarro1 lo de cualquier economía agrícola puede ser estimada tomando en cuen ta el grado en que el ambiente natural puede ser cambiado y las técn $\bar{i}$ cas utilizadas con este fin" (Dumont, 1975:142). Los símbolos de es= te proceso, al decir del mismo Dumont, son el arado y el campo arado.

Hemos presentado a grandes rasgos lo que consideramos es un sis tema agrícola. Thorner resume las principales caracteristicas de éste de la forma siguiente:

Hemos definido la economía campesina en términos de la pre dominancia de la agricultura, tanto en la producción como en la población trabajadora. Hemos requerido la existencia de un territorio estatal y la separación entre campo y ciudad. Hemos indicado que la unidad caracteristica de producción debe ser la familia campesina con una doble orientación, esto tanto para su propia subsistencia como para el gran mundo situado más allá de la aldea. Debemos 
enfatizar que ninguno de estos elementos solos serán suficientes para determinar si una economía es o no en verdad una economía agrícola. Todos estos elementos deben ser buscados juntos y deben relacionarse con la economía de todo el pais (Thorner, 1975:207-208).

Aunque Thorner enfatiza la producción familiar, la expansión in dustrial y de los métodos modernos de organización y administración empresarial en la zona rural ha modificado este patrón tradicional en cuanto a la función familiar, quitándole el rol productivo y creando el obrero agricola, que es una categoría diferente de trabajador rural. Andrew Pearse $(1970: 14)$ se refiere a este punto y señala, refiriéndose a la América Latina, que "los valores, las normas organizacionales, ideológicas, prácticas económicas, dinero y medios técnicos de las grandes ciudades influyen en el sector rural de tal forma que alteran la rutina rural y las estructuras a través de todo el continente".

A partir de este marco teórico, haremos una revisión del desarrollo de la agricultura dominicana, con énfasis en la descripción histórica. Nos dedicaremos muy brevemente a la era colonial, definiendo ésta de forma muy general desde la colonización hasta la independencia, incluyendo el período haitiano. Dedicaremos más tiempo al periodo republicano, con énfasis en las últimas décadas del siglo pasado, cuando la estructura agraria toma su forma distintiva actual.

Como nuestro interés está en los componentes estructurales del sistema, dedicaremos poco tiempo a los problemas actuales, por considerar que estos son en gran parte la resultante de la estructura agraria introducida en el siglo pasado y que no ha sufrido reformas sustanciales en lo que va de siglo. Concluiremos con un esbozo de aná lisis de la relación entre el modelo y la realidad.

\section{LA ERA COLONIAL}

Richard Morse (1973:82) señala un punto de gran importancia para el desarrollo posterior al descubrimiento de lo que sería la socie dad dominicana. Dice que "la mayor incongruencia de la historia institucional de América Latina reside en que gran parte del trabajo pro ductivo ha consistido en la extracción de bienes de la tierra y deT subsuelo, aunque quienes se establecieron en el área (así como los in migrantes de épocas posteriores) atravesaron el océano con la idea de la ciudad en mente". En efecto, si se observa con cuidado el estable cimiento de la colonia de Santo Domingo, se llega a opinar igual que Morse. 
Los primeros años de la colonia se caracterizaron por la extrac ción de oro y de tributos, para lo cual los españoles tenían a su dišs posición la mano de obra indígena, pero cuando se estableció una admí nistración colonial definitiva con Fray Nicolás de Ovando, las cosas cambiaron. Ovando vino a Santo Domingo con órdenes bien precisas "en cuanto a la defensa de los intereses reales y al ordenamiento de la vida social de la Colonia" (Moya, 1974:60) y con el "fin de estabilizar los establecimientos coloniales previstos, se dispuso que los coIonizadores vivieran en la Española agrupados en pueblos" (Lamb, 1977: 48).

Ovando fue un constructor de ciudades. Quizás su obra maestra fue Santo Domingo y en ella concentró todo el poder de la corona, con virtiendo el resto del territorio en satélites subsidiarios de Santō Domingo:

En la orilla del río, Ovando proyectó una ciudad que fuera símbolo de seguridad y autoridad. Escogió el lugar para la fortaleza, hizo el trazado de las calles principales alrededor de la plaza central, designó solares para casas de comercio y moradas particulares y ordenó que los edificios se construyeran de madera y piedra (Lamb, 1974:81-82).

Esta mentalidad urbana que guió el establecimiento, organización y administración de la colonia, y que se revela en el papel mono pólico de Santo Domingo, se ha reflejado, una veces más y otras menos, en toda la historia dominicana hasta el día de hoy. La agricultura se vio sensiblemente afectada por esta actitud, como se explicará posteriormente. Igualmente, las costumbres españolas en cuanto a la alimentación harían que los colonos recibieran gran parte de sus bienes de consumo de España, los que complementaban con productos locales, a los que tenían que acostumbrarse, cultivados por la población indíge na. Este es el período de la economía minera, que decae pronto,lo que obliga a los colonos a emprender el primer esfuerzo serio de crear una economia agrícola. Moya (1974:67) relata "los grandes esfuerzos que hicieron todos aquellos que tenían algo que perder por ver si podian reorientar la economía de la lsla tratando de desarrollar la agricultura importando labradores y haciendo experimentos con semillas europeas para determinar qué cultivos podían resultar rentables". De aquí surgió el primer intento de plantación azucarera que gozó del apoyo financiero de la corona y de la mano de obra del negro esclavo.

Esta comenzó a crecer rápidamente y con ella, cierto grado de ruralización de la colonia y descentralización del poder político hacia las zonas alrededor de los ingenios azucareros. Entre 1536 y 1565 , barcos españoles que traían mercancías del viejo continente "llevaban a su regreso sus bodegas cargadas de los productos de la tierra, 
azúcar, cueros, cañafístola, guayacán y sebo, entre otras cosas" (Moya, 1974:85). Sin embargo, para principios del siglo XVII la industria entró en crisis, malográndose asi el primer intento de crear un sistema agrícola basado en la plantación sostenido con caráctercomercial, por la mano de obra esclava.

La respuesta fue la conversión de la colonia en ganadera con el surgimiento del hato, que impidió por siglos el desarrollo de la agri cultura y en cambio se alimentaba de una economía de subsistencia, cu ya unidad de producción era el conuco, cultivado por esclavos. Alrededor del hato surgió un nuevo tipo de organización social que perduraría por siglos y aún se manifiesta en muchos de los aspectos de la vida dominicana. El hato, más que una unidad económica, era en su tiempo una sociedad autocontenida con escaso contacto con el mundo ex terno, similar en muchos aspectos a la hacienda señorial descrita por Tannenbaum (1962).

El surgimiento del hato coincidió con el decaimiento de la importancia de la colonia y sirvió en el siglo XVII de base para mantener la colonia durante ese largo período de crisis del imperio español, cuando las emergentes potencias del norte europeo arrinconaron a España en Europa y le disputaron con relativo éxito su dominio ultramarino. Consecuencia de estos hechos fueron las devastaciones realizadas por el gobernador Osorio, quien redujo a casi un tercio de su territorio la colonia y dio paso a los establecimientos franceses del oeste y finalmente a la República de Haití.

Para mediados del siglo XVII, la corona inició una nueva politi ca administrativa de la colonia, fomentando la repoblación del territorio aún no ocupado por los franceses. Los nuevos habitantes, de ori gen canario, venian con destrezas para la agricultura, a la que se de dicaron, especialmente al tabaco, que ya venía cultivándose por algún tiempo en pequeña escala en los al rededores de Santiago para ser vendido a los franceses. En el siglo XVIII la corona española fue traspasada de los Habsburgo a los Borbones, y con éstos se inauguró una nueva politica administrativa del imperio americano, la cual se refle jó en la colonia de Santo Domingo, con nuevos repoblamientos, la creā ción de nuevas villas, una liberalización del comercio y la aperturā de puertos al libre comercio con naciones que no estuvieran en guerra con España. El comercio del tabaco floreció lentamente, pero se sentaron las bases para que posteriormente, en el siglo XIX, se convirtiera en el principal producto de exportación.

Los eventos políticos incidirian en el curso de la historia de la colonia. La parte francesa se había convertido en el principal mercado del este español, y este intercambio, unas veces legal y otras ilegal, pero de una forma u otra, permitió la supervivencia de la 
economía hatera de Santo Domingo con sus efectos consecuentes en el re tardo del desarrollo de la agricultura (c.f. Silié, 1976).

Entre tanto, el corte de maderas preciosas para exportación comenzó a crecer, añadiéndose a los factores retardatarios del surgimien to de la agricultura, centrada en forma de cultivo del tabaco en eT norte, en el valle del Cibao, coexistiendo con una economía de subsis tencia.

Durante el período haitiano, las nuevas autoridades se preocupa ron con escaso éxito de fomentar la agricultura, incluyendo la trans formación de la propiedad tradicional de la tierra en terrenos comune ros. Las disposiciones haitianas de repartir tierra para la agricultura a costa de los hatos creó serios conflictos, en los que la sangre y el asesinato fueron frecuentes. En los cortes de madera del sur, los haitianos quisieron igualmente imponer restricciones infructuosamente, ya que los dominicanos recurrieron en respuesta al contra bando.

\section{EL PERIODO REPUBLICANO}

Al declararse la independencia en 1844, los dominicanos heredaron un paîs sin agricultura y con una débil base de sustentación económica. Una de las primeras tareas era precisamente crear todos los mecanismos que definen el Estado moderno, tanto en lo político como en lo económico. La potencialidad agrícola de la sociedad dominicana era propicia para este intento, que de tener éxito integraría el país al comercio internacional, convirtiéndolo en fuente de riqueza y bienestar general.

Sin embargo, a las debilidades estructurales heredadas de un lar go periodo coloníal, se unió la circunstancia de la guerra contra Ha ti, que distrajo el tiempo necesario para dedicarse a poner en orden la casa. Hombres y recursos fueron desesperadamente distraídos a los escenarios de la guerra contra el vecinoque no desistía de sus intentos de mantener el predominio sobre la recién independizada nación. Esto se tradujo en un abandono de las tareas agrícolas, descuidándose aquellos cultivos que no eran destruidos al servir de campos de batalla.

Durante este periodo de la primera república no hubo mejoras sustanciales en el panorama agrícola dominicano, vale deciren toda la economía. En 1856 Bonó (1964:71) decía en el Senado: "Un gran mal aqueja al país, señores, y es el Ejército permanente. Este Ejércíto no deja al hombre trabajar, le roba su tiempo y no le da compensaciones", y en su famoso ensayo "Apunte sobre los Cuatro Ministerios de la 
República", volvía sobre el tema, siendo más explícito acerca de la agricultura. En sus apuntes sobre la Clase Trabajadora (1974) descri be la situación del campesino de forma sencilla y magistral, que reve la toda una organización social:

Un joven labrador 11 egado a su mayor edad quiere emancipar se. Su padre pobre estanciero o ranchero, no le da ni pué de darle más que algunos cordeles de tierras de montes. Eñ el primer año, por un esfuerzo, el mozo tala, tumba, cerca, habita y siembra unas tantas tareas de maíz, plátanos, yuca y en el segundo año, por otro esfuerzo, apropia materia les para un bohío que fabrica con su hacha y su machete. Ya tiene vivienda y comida para algún tiempo y entonces se casa. La mujer comparte sus cuidados, sus faenas, pero además de sus consumos personales aporta los de partos, en fermedades e hijos. La familia harta y a cubierto, está desnuda, enferma, sin médicos ni medicinas y la vista fija en el jefe que la ha creado, todo lo espera de él.

Este ensayo, escrito en los años ochenta del siglo pasado, tiene aún hoy una vigencia dramáticamente increíble, aunque la situación descrita se ha multiplicado varias veces por el crecimiento de la población.

Las guerras de independencia, la anexión a España y la consecuente guerra de Restauración mantuvieron, por no decir empeoraron, la situación. Si hubo algún progreso, fue en el cultivo del tabaco que siguió exportándose a Alemania y que constituía prácticamente el único renglón de importancia agrícola en el país. El hato había perdido su posición económica y los cortes de madera habían entrado en crisis. Mientras, la población seguía manteniéndose de la economía de subsistencia.

Sin embargo, no se puede decir que hubiera una crisis alimenticia en el país en ese momento. Había una escasa población, mucho menor en los centros urbanos. Así, no había una gran presión sobre la producción del conuco, y una vez que el campesino tomaba para su propia subsistencia los bienes que necesitaba para él y su familia, mercadeaba en la plaza local algún escaso excedente a cambiode otros bie nes que no producia. Esto era suficiente para suplir la aldea ce cana.

La falta de caminos era un impedimento para el desarrollo de un mercado interno. Así, cada centro urbano tenía en sus alrededores una red de conucos que le aportaba para su subsistencia, y los bienes que éstos no suministraban, eran importados, aunque pudieran producirse en el país, o se estuvieran reproduciendo en otros lugares pero que no 
tenían salida a un mercado nacional. Esta situación no escapó a los comisionados norteamericanos en 1871, quienes comentaron:

Como una prueba de la condición de atraso en que actualmente se halla la agricultura dominicana, puede citarse el hecho de que la Comisión, durante sus expediciones en el interior de la isla, con frecuencia se encontraron con que habila azúcar de remolacha producida y refinada en Fran cia; mantequilla y quesos importados de Dinamarca, y $1 e^{-}$ che condensada producida en los Estados Unidos, pero rara vez encontráronse las comisiones con artículos similares fabricados en la isla (Informe, 1871:18).

Hazard (1974:274) relata que cuando se propuso viajar desde San to Domingo al interior, "la gente parecia pensar que uno debía esta $\bar{r}$ loco o esperar algún misterioso beneficio de tal viaje'". Abad (1888: 171) decía que la comunicación entre el norte y el sur era "lenta, muy penosa e imposible durante la larga temporada de 1luvias". En 1887 el entonces presidente Ulises Heureaux comentaba que se había celebra do "mucho en Santiago y aquí la feliz ocurrencia de Wash en llevar a Santiago una carreta cargada desde Puertc Plata". Deschamps (1907: 149) decía a principios del presente siglo que el viaje de Santiago a Montecristi podía hacerse en carreta durante la época de sequía y, más aún, tan tarde como 1922, el interventor norteamericano de aduanas es cribía en su informe anual.

Por primera vez una apreciable cantidad de plátanos y otros productos perecederos fueron embarcados desde los distritos rurales en el norte a los mercados de la capital. Asi los pequerios propietarios recibieron un beneficio en 1922 de productos que antes de la apertura de caminos no habían representado prácticamente ningún valor.

Después de la Restauración de la República, el país estuvo embarcado en un largo periodo de inestabilidad, producto de las guerras regionales de corte caudillista, que duró hasta 1879. A esta inestabilidad hay que añadir la desconfianza mutua entre el hombre de campo y el urbano, que tenía un alto ingrediente político, aparte del econó mico, debido a la desigualdad en el intercambio comercial entre ambas zonas. Bonó (1964:289) afirmaba que los campesinos no podían apreciar a la gente de la ciudad ni como amigos ni como hermanos, ya que los primeros tenían que soportar la pesada carga de vestir, mantener y alimentar al urbano, en adición al hecho de que las autoridades locales de las ciudades "ejercían sus funciones las más de las veces co mo una verdadera calamidad para el que trabajal". Por esta razón, si= guiendo la línea de pensamiento de Bonó (1964:288), "el habitante del campo casi siempre abraza espontáneamente el partido contrario al que 
siguen las ciudades con el objeto de combatirlas, destruirlas o humillarlas.

Asi, las condiciones sociales, económicas y politicas no eran propicias para el desarrollo de un sistema agrícola. A éstas hay que agregar las conexiones con el mercado externo, que beneficiaban la per manencia de la desarticulación económica nacional en regiones cuasiautónomas, autosostenidas por la economía de subsistencia. Hazard $(1974: 228)$ recoge la respuesta que le dio un campesino dominicano cuando le preguntó por qué no utilizaba la tierra extensivamente. "¿Para qué - le respondió el campesino-, quién los quiere? No hay mer cado para ellos y nosotros no los necesitamos, si tenemos ya todo $1 \overline{0}$ que nos hace falta sin tener que preocuparnos".

Las disposiciones municipales desestimulaban el intercambio interno de artículos esenciales de consumo diario. Las municipalidades solian cobrar impuestos sobre los productos que 1 legaban a los centros urbanos para su sostenimiento, pero los efectos eran negativos, en ra zón de que el campesino se eximía de llevar sus productos al mercado local cuando no veía un beneficio en ello, como reconoció en 1860 el Ministro de Interior y Policía, quien decía en su memoria anual que estos impuestos constituían un obstáculo para el desarrollo agrícola. Bonó (1964:296) insistía en que ya el país se encontraba disfrutando de paz y por lo tanto "no hay motivos plausibles que justifiquen un au mento de impuestos para agregarlos a los que tan afanosamente paga $e^{T}$ dominicano". De acuerdo a sus estimados, los dominicanos en 1884 pagaron un 200 por ciento en impuestos sobre el precio de artículos de consumo diario. Según decía Bonó (1964:414), los impuestos se elevaron a cifras increíbles para aumentar los beneficios a los Ayuntamien tos "para adornar los pequeños centros urbanos que poseemos con todas las galas de las ciudades ricas y florecientes".

El gobierno trató de crear un sistema agrícola con éxito relati vo. Una legislación especial reservó el comercio local a los domini= canos. En 1845 se estipulaba que los comerciantes extranjeros tenían que pagar el triple de los impuestos que pagaba un dominicano. Los ex tranjeros radicados en puertos activos tenían que pagar cuatrocientos pesos en moneda fuerte (divisa) por una patente, mientras los dominicanos sólo pagaban ochenta pesos en moneda fuerte. A pesar de estas disposiciones, los extranjeros, con sus conexiones internacionales y con mayor destreza y conocimientos comerciales, permanecieron en una posición superior. Esto se refleja en el informe de los comisionados norteamericanos que visitaron el país en 1871 , en donde se dice sobre Santiago, y esto se extendía a todo el país, que ésta era una ciudad "de comerciantes que gobiernan a los comerciantes inferiores del inte rior y que a su vez son gobernados por los comerciantes extranjeros de Puerto Plata y Santomas" (Informe, 1871:132). 
Igualmente el gobierno trató de proteger la comunicación maríti ma para beneficio de los dominicanos, intentando crear una flota na= cional que cubriera el intercambio nacional mediante el uso de embarcaciones pequeñas. Así, un decreto de 1882 establecía que el cabotaje era ocupación exclusiva de dominicanos. Sin embargo, estas disposiciones, a pesar de un relativo mejoramiento de la flota nacional, la falta de una estructura de mercado nacional y la orientación hacia el mercado internacional, no ayudaron mucho. La creciente población urbana, que demandaba más bienes esenciales de origen agrícola, no hacía todavía suficiente presión como para modificar la agricultura de subsistencia prevaleciente. La construcción del ferrocarril, en cambio, significó un gran avance en el desarrollo del mercado exterior.

Los cambios en la estructura agrícola del país se producirian a partir de las dos últimas décadas del siglo pasado. Este proceso no puede verse aislado del político. Como habíamos señalado, a la Restauración siguió un período de inestabilidad hasta 1879. Ese año Gre gorio Luperón ocupó la presidencia provisionalmente e inauguró un periodo de estabilidad que duraría veinte años y cuya figura estelar sería Ulises Heureaux. Es durante este período cuando se crea la estructura agrícola más importante del país y que todavía perdura con algunas adiciones y mejoras, pero esencialmente sigue siendo la misma.

El primer paso dado fue la desarticulación regional. Esto significó la transferencía del poder político al ejecutivo, que logró monopolizarlo, de tal manera que aún hoy el Poder Ejecutivo es la fuerza política más importante del país. Pero la desarticulación política de las regiones, que se tradujo en cierto grado de integración nacional no finalizado hasta la Era de Trujillo, significó también quitarles su base de sustentación económica. A esta situación de origen esencialmente nacional, se añadió un acontecimiento internacional imprevisto, la caída de los precios del tabaco en el Norte.

Muy brevemente, para dar una idea del gran sentimiento regiona1 ista prevaleciente, basta con citar a Bonó (1964:461), quien advertía a Luperón en 1882 diciéndole que desde hacía cuatro años "el Cibao domina rotundamente y Santo Domingo no está tan acostumbrado a se mejante dominación declarada, para que lo soporte pacificamente por más tiempo". Welles $(1975: 1-506)$, refiriéndose al mismo tema, decía que el favoritismo de Heureaux por los comerciantes del sur "aumentaría el descontento en el Cibao". Hostos (1939:1-124) se quejaba: "Es lamentable el estado moral de un país, en donde el reconocimiento público de los méritos de una de las fracciones de su suelo es impopula ridad en las fracciones restantes".

Para lograr la desarticulación regional, Lilís en primer lugar articuló su base de poder mediante una coaliciôn de líderes locales en 
el Sur y el Este, y después se impuso en el Norte enfrentándose a Lu perón. De esta manera, para 1887 había logrado el control absoluto del país. Heureaux había dicho en 1882, antes de su primera elevación a la presidencia: "El gobierno que nazca de la actualidad practi cará la misma doctrina. Que vengan todos los hombres, no importan los errores pasados $n \mathbf{i}$ sus convicciones: Todos hemos errado. Que sirvan a la Patria y son amigos del gobierno".

Es to no era retórica electoral. Una vez en el gobierno, integró por primera vez en el país hombres representativos de todas las regiones, sin tomar en cuenta filiaciones politicas. Pero a un alto costo, porque la alianza se basaba en prebendas y privilegios especia les para los que aceptaban su política, o el exilio, la cárcel o la muerte a los opositores. El mismo decía que no hacía politica de afec tos ni de partidos y escogería los hombres "donde los encuentre y apre ciaré y consideraré conforme la conducta que observen para conmigo".

En honor a la verdad, la transformación de la agricultura en el siglo XIX no fue obra exclusiva de Lilis. Ese era un sentimiento pre valeciente desde siempre, como se pudo apreciar en paǵinas anteriores, pero es cierto que este proceso se aceleró como nunca durante la larga dictadura de Lilis, con el decidido apoyo gubernamental. La orien tación básica de esta política, compartida igualmente por todos los gō bernantes y pensadores dominicanos desde Santana hasta el día de hoy, era la de crear una agricultura que permitiera al país integrarse al mercado internacional.

Este fue un largo y penoso proceso. Se inició con caracteristi cas regionales, como un enfrentamiento contra el hato. En primer lugar fue el tabaco en el norte y posteriormente la industria azucarera en el este, a tal punto que la ganadería se convirtió en una actividad marginal. Según relata Bonó (1964:263), los hateros de San Francisco de Macorís "han vendido y siguen vendiendo (en 1881) sus tierras a agricultores de Moca y Santiago y se internan a los ranchos distantes, que aún desiertos, les permiten continuar su vida pastoral". Otros, que no vendieron ni se marcharon, se convirtieron en agricultores, pero tuvieron que aprender un nuevo oficio que en palabras de Bonó (1964:223) era "duro y penoso".

Ambas actividades, la agricultura y la ganadería, eran incompatibles, lo que se refleja en la expresión "criar mata la siembra". Ya vimos los inconvenientes que tuvieron que enfrentar los haitianos cuan do intentaron substituir la ganadería por la agricultura. A finales de siglo, la expresión popular puede parafrasearse de otra forma: "la agricultura mató a la ganadería". La práctica de la crianza libre que prevaleció por siglos tenía que ser terminada si se quería el desarrollo agrícola, como reconocía Emiliano Tejera (1941:191) quien en 
el siglo pasado se preguntaba si valía la pena tener al cerdo vagando como "señor de campos i poblados", ya que en general la ganadería no puede "liberarnos de ser tributarios del extranjero en carnes, leche, mantequilla, sebo y demás productos que de esa crianza libre se obtie nen".

A instancias de Tejera, Lilís promulgó la ley 3522 , mediante la cual se prohibía absolutamente "soltar en el territorio de la Repúbli ca animales dañinos de cualquier especie que sean". Sin embargo, la presión contra el gobierno fue tal, que Lilís se vio obligado a revocar la ley. Tejera, frustrado por el fracaso, le escribió su opinión de que "librar la agricultura de la injusta carga que pesa sobre ella, era hacerle un gran bien a este pais, que debe ser eminentemente agri cultor".

Esto sucedía en 1895 , casi a finales de siglo, cincuenta años después de la independencia. Pero éste no sería el único episodio en el largo proceso, aún inconcluso, de crear un sistema agrícola. Este comenzó en el norte, después de la Restauración, alrededor del tabaco. La agricultura tenía sectores especializados y diversificados con pro ductos de exportación y de subsistencia, pero el rey del comercio exterior era el tabaco, el cual no dejaba de tener serios problemas, lo que lo hacía sumamente frágil para sustentar el desarrol lo nacional. Abad (1888:317) nos relata esto:

El tabaco viene cultivándose desde tiempo inmemorial en la rica región del Cibao, sostenido, desde los primeros tiempos, por el comercio de Hamburgo, que ha hallado en nuestra hoja una clase de rendimiento para sus manipulaciones, siempre que se mantenga en los precios bajos a que ha sabi do limitarlo. Esta influencia del mercado de Hamburgo ha sido decisiva y fatal a nuestra hoja, que no ha tenido estímulo para mejorar en calidad, porque los compradores de aqui, procediendo como agentes de las casas alemanas, y los cultivadores, para responder a sus compromisos, escojían (sic) para sus siembras tumbas recientes de montes y tierras negras y gruesas.

En los años ochenta el mercado tabaquero comenzó a declinar, pa radójicamente cuando empezaba a mejorar su calidad. Sin embargo, eT mercado a lemán estaba más interesado en la cantidad que en la calidad. La baja calidad de la hoja hacia que se vendiera más barato que otras variedades. Por ejemplo, en 1882 el periódico El Eco del Pueblo informaba que "de los tabacos que en los puertos alemanes se reciben, el de Santo Domingo, proveniente de la actual cosecha, ha sido clasificado ... en el más bajo precio por ser la hoja, no sólo de mala cali dad, estar peor condicionado, sino que muchos bultos han salido 
podridos". Luperón, entonces en Europa, informaba que hacía diez años que "el gobierno de Austria resolvió no comprar más el tabaco de Santo Domingo, cansado de encontrar en los serones más de la mitad de las hojas podridas". Bonó (1964:268), gran defensor de este cultivo, quien decía que el tabaco era demócrata y el cacao ol igarca, no tuvo más remedio que reconocer, no sin un dejo de amargura, este hecho;"Asi ha sucedido, por desgracia, y el comercio es quien por de pronto ha re cibido la primera herida".

Esta situación coincide con un replanteo de la economía y la búsqueda de otras salidas al atraso del país. Es interesante el deba te que recoge la prensa de esos días sobre el desarrollo agrícola. En 1889 el gobernador de Santiago reportaba que "la depreciación del tabaco ha forzado (a los agricultores) a fijar la vista en otros cultivos". Abad (1888:292) advertía contra el monocultivo, diciendo que "' ir a los mercados, en estos tiempos de grandes luchas industriales con un solo artículo, sea éste azúcar, café, tabaco, algodón, cacao, y dejar la casa desprovista de lo necesario a la vida de la familia, es querer exponerse a acostarse sin cenar". Manuel Castillo (1964: 405), coincidiendo su planteo con el de Abad, decía en 1895 que "negar la capacidad productiva de riqueza a otros frutos como el cacao, el café y otros... es un aserto peligroso".

Muy pronto el café y el cacao comenzaron a competir con el tabaco, como resultado de una legislación especial para mejorar y diver sificar la agricultura. Asi, en 1880 el gobierno creó juntas de agri cultura en cada municipio, se dispuso premiar a los agricultores con parcelas de tierra que oscilaban entre una y diez tareas si se distin guían en su trabajo. Ese mismo año un decreto autorizó la importación, libre de impuestos, de cualquier maquinaria destinada a la agri cultura y a las instalaciones industriales y excluía a los agricultores del servicio militar.

También se establecieron fincas modelo y el gobierno asignó sesenta mil pesos para fincas modelo de algodón y tabaco en Azua y Bara hona. Se destinaron terrenos para zonas agrícolas que debían ser ut lizados exclusivamente para la agricultura y el periódico Listín Diario reportó en 1893 una disposición del gobierno mediante la cual se premiaría a aquellos campesinos que plantaran dos mil y más matas de café o cacao en un período de diez años. El propietario de estas plan taciones estaria exento de cualquier servicio military recibiria ciñ cuenta pesos por cada dos mil plantas.

En 1887 el gobernador de Azua escribía que la cosecha de café había sido tan exigua que "escasamente alcanzará para el consumo local", pero el gobernador de Samaná informaba que el cultivo de cacao se estaba extendiendo y agregaba que "no cabe duda éste será, como es 
hoy, el principal fruto de exportación" de esa provincia. Dos años después el gobernador reportó que en Samaná existían 618,550 matas de café, 630,000 de cacao y 17,498,607 de tabaco.

Para notar el impacto de esta nueva política de desarrollo agri cola, basta considerar que en 1868 el tabaco representaba el 88 por ciento de las exportaciones dominicanas. En esos tiempos, el cacao representaba menos del uno por ciento y el café un escaso cuatro por ciento. El azúcar comprendía algo más del ocho porciento de las exportaciones. Para 1893, la exportación de tabaco se había casi dupli cado, pero el café aumentó en casi ocho veces y el cacao en más de un cien porciento. Para 1900 el cacao reemplazó al tabaco como principal cultivo de exportación en el norte.

Sin embargo, ningún cultivo introducido en esa época logró tanta prominencia como el azúcar, que rápidamente, hasta hoy, se convir tió en el principal cultivo de exportación del país, y con su desarrō 110 afectó toda la vida social y política del país. Si un cultivo lo gró integrar plenamente el país al mercado internacional, ése fue $e^{\bar{T}}$ azúcar. La industría azucarera se benefició más que cualquier otra actividad de la nueva orientación política del gobierno de Lilis. De acuerdo con Bryan (1978:92), el gobierno dominicano "vio cierta venta ja al otorgar incentivos a los inversionistas extranjeros para que en traran en el negocio de producción azucarera en la República". Las concesiones de privilegios especiales, tales como garantizarles la tie rra e importaciones libres de impuestos, fueron incentivos importantes para el desarrollo de este cultivo, como señala Bryan (1978:93):

Los intereses azucareros podían... importar equipo para sus fábricas de azúcar y edificios complementarios, unidades de transportación en las fincas o para transportar azúcar a los muelles, asi como combustible, sin pagar al gobierno dominicano los impuestos correspondientes.

La industria azucarera introdujo un nuevo patrón de tenencia de tierra: el latifundio. Esta concentración de tierras en pocas manos hizo que Bonó (1964:281) dijera que una aglomeración de máquinas, tre nes, vagones, edificios, cañaverales, destruyó los pequeños conucos $\bar{y}$ su ganado" y "con ellos la subsistencia de la ciudad y trabajadores".

Con la estructura tradicional agrícola, predominó la tenencia en forma de terrenos comuneros, una derivación de los patronos colonia les de tenencia. Este tipo de propiedad consistia en "parcelas de tie rra de propiedad común de varias personas sin división entre los propietarios" (Bishop y Merchant, 1976:114). Bonó (1964:222) explica su origen diciendo que el propietario original asignaba parcelas a sus 
herederos y éstos a su vez a los suyos y así sucesivamente. Al crecer la familia, "se multiplicaban las divisiones de las tierrasen las cuales ingresaron los emigrados, por compra, o por alianzas con la fa milia, quedando empero unipersonal el derecho de propiedad de todos en el sitio, que es hoy comunero sin limitaciones de ningún género".

Hacia fines del siglo pasado surgió la necesidad de mensurar y definir los límites de la propiedad, que no se logró hasta el gobierno de Ramón Cáceres en este siglo. Abad (1888:264) propugnaba por la desaparición de esa "forma anómina" de tenencia y Bonó (1964:82) decía estar convencido de que no habría agricultura si no se garantizaba la propiedad privada de la tierra, y en 1881 consideraba que "sólo el gobierno puede promover la división regular y equitativa de los ran chos entre sus poseedores actuales".

Sin embargo, la propiedad privada de la tierra comenzó a introducirse amparándose en la misma forma de traspaso de terrenos comuneros, destruyendo estos de paso, a tal punto que en 1884 Bonó decía: "He hecho ver la transformación del Este; la traslación a título casi gratuita de su propiedad a manos de nuevos ocupantes encubiertos bajo el disfraz del progreso" (c.f.Luperón, 1939:|11-149-150). Deschamps (1970:131) explicaba a principios de siglo cómo era este procedimiento:

Uno de los medios mas expeditos y económicos de adquirir la propiedad de terrenos adaptables a la agricultura o a la pecuaria, consiste en la compra en unos cuantos pesos de los 1 lamados terrenos comuneros, grandes extensiones de tierras indivisas, cuyos títulos de propiedad no representan su valor, sino acciones del terreno.

Este fue el intento más serio y fructífero, aunque incompleto, para crear un sistema agrícola. Un examen superficial de la situación de la agricultura actual comparándola con la de este período, per mite concluir que las bases del sistema agrícola se sentaron en esa época. Azúcar, café, cacao y tabaco siguen siendo los productos prin cipales de exportación. La gran parte de los productos de consumo diario aún se cultivan siguiendo las técnicas tradicionales de la eco nomia de subsistencia que ha prevalecido por tantos siglos en el país. No es aventurado decir que, por ejemplo, los elementos esenciales de la dieta diaria dominicana tienen su origen en el conuco. Sólo el arroz, introducido en este siglo en gran escala, se cultiva en planta ciones al tamente comercializadas.

La función primordial de un sistema agrícola es proveer los bie nes esenciales para la vida, respondiendo a criterios tales como los señalados anteriormente en la primera parte de este artículo. Las 
bases de éste fueron creadas a partir de una constelación de unidades de producción desintegradas y con un alcance muy $1 \mathrm{imitado,} \mathrm{pero} \mathrm{aún}$ no se ha logrado el desarrollo suficiente para decir que la República Dominicana es una sociedad agricola. Quizás sería más conveniente ha blar de un país con un sector poblacional de cultivadores.

En lo que va de siglo veinte, ha habido crecimiento en algunos de los elementos constitutivos de la base agrícola creada, pero muy poco cambio cualitativo orientado al desarrollo de un sistema agrico1a. Por ejemplo, no fue hasta 1909 que un derivado del azúcar, la me laza, surgió como una nueva empresa con posibilidades de exportación y escaso uso doméstico. En el informe del interventor de aduanas de 1911 se dice al respecto:

La producción anual de melazas es estimada en 5,000,000 de galones, pero de esta cantidad sólo una parte relativamente pequeña es consumida en la manufactura de alcohol. El resto en años anteriores era botada, dañando asi por contaminación las corrientes cercanas a donde se encuentran localizados los ingenios.

El mismo informe se refiere a los problemas tradicionales del tabaco: "criticismo por el secado imperfecto, fermento y clasificación fue expresado como es usual por los compradores europeos". En ese año de 1911 el gobierno estableció una estación experimental para mejorar los conocimientos de los tabaqueros y mejorar la calidad del cultivo. En 1913 el mismo interventor informaba sobre el Cacao, que como se vio, fue introducido a nivel comercial a finales del siglo pasado, di ciendo que la producción de éste "es suprema, ya que de la producción mundial en 1913 de 68,328 toneladas, exportó 19,133 toneladas, el treinta porciento del total, colocándose a la cabeza de una lista de veinte naciones productoras de cacao'. Sobre la ganaderíase decía en el informe correspondiente a 1921:

Una atractiva posibilidad comercial para la República puede ser el ganado, su cría, desarrollo y exportación. Localizada entre Cuba y Puerto Rico... ambos paises bien poblados, no producen suficiente ganado para suplir la demanda local. Santo Domingo produce actualmente un excedente, y con poco cuidado. Sin embargo, la isla no disfruta de un mercado de exportación, al tiempo que Cuba trae su ganado de las lejas Colombia y Venezuela mien tras Puerto Rico es un fuerte importador de productos de carne"l.

A pesar de estas posibilidades para el surgimiento de la ganade ría dominicana, no fue hasta 1935 que se instaló la primera fábricá 
Por otro lado, en el curso de este siglo se intentó la introduc ción de nuevos cultivos, algunos con éxito y otros no tanto c de corta duración. Veamos el caso del algodón. Desde finales del siglo pa sado se pensaba en éste como un buen cultivo para el país. De habe $\bar{r}$ tenido éxito, éste hubiera podido impulsar una significativa industria textil. En 1910 se registra el algodón como "un nuevo elemento en el comercio dominicano", según el informe de ese año del interventor de aduanas, quien consideraba que "Santo Domingo posee un área al godonera muy rentable". En 1908 se habia comenzado el cultivo y mercadeo de éste en el noroeste. En el 1910 se expresa en ese informe un gran optimismo por las ventajas y futuro de este cultivo.

Mientras la cantidad de algodón exportado no fue grande, sin embargo el relativo incremento en la tierra cultivada y rendimiento ha sido tal... que la conclusión natural garantiza que este producto tomará rápidamente lugar como un producto de magnitud en conexión con otros productos cultivados en Santo Domingo".

Dos factores se combinaron para beneficiar el desarrollo de este nuevo cultivo, al cual se dedicaban pequeños productores. El primero fue, justamente, la falta de recursos de éstos para dedicarse a otros cultivos que requerían una gran inversión de capital y un largo período de espera para recuperarlo, como el cacao. El segundo factor es explicado en el informe del interventor de aduanas de 1911:

Estimulado por exportadores en Montecristi y Puerto Plata a través de la distribución de semillas más selectas y la diseminación de información sobre métodos más deseables en la preparación del terreno, cultivo, etc., se ha notado una continua actividad y decididas ganancias en la producción de algodón.

Los productores se multiplicaron por seis y mientras en 1911 se exportaron 170,414 kilos, en el lapso de un año, en 1912, la exportación aumentó a 350,042 kilos. Sin embargo, en 1914 se "mostró una considerable baja" debido a "la guerra europea (por lo cual) práctica mente no hubo mercado para este algodón, cuando ya estaba listo para embarque".

Este hecho no influyó para que se aprovechara la oportunidad de crear una industria textil dominicana, como sucedería en otras situaciones que dio paso a lo que la CEPAL ha llamado crecimiento hacia adentro". En 1920, en el informe del interventor de aduanas, se revela una disminución en la balanza de pagos de más de cinco millones 
sobre las cifras de 1919, debido "a las enormes importaciones de bienes de algodón y otras mercancías". En ese año se exportaron 57 tone ladas y en 1927 la exportación fue de 59 toneladas. En 1937 se hicie ron nuevos intentos para revitalizar este cultivo, pero sin éxito, pues, como se sabe, éste no es un producto de gran importancía para el consumo doméstico $y$ mucho menos para la exportación.

El caso del arroz es diferente. Este se cultivaba en pequeñas cantidades prácticamente para autoconsumo, mientras en otros lugares del paîs, en donde éste no se producía, habia que importarlo. En 1894, según Emiliano Tejera (1941:190-191) se desembarcaron en el puerto de Santo Domingo 2,938,373 libras. En 1908 la importacióncreció a $16,221,141$ libras y en 1909 a 19,368,407 libras. En 1925 se incluyó el arroz entre los cultivos que el gobierno quería fomentar, junto con las papas, las cebollas, las habichuelas y el maiz. El informe del in terventor de aduanas de 1935 dice al respecto:

La importación de arroz durante los últimos siete años ha Ido disminuyendo anualmente desde un tope en 1929 de 27,790 toneladas valoradas en $\$ 2,115,287$, a 9,456 toneladas con un valor de $\$ 354,414$ en 1925 . Tres causas principales con tribuyen a la reducción de la importación de arroz: El gran incremento de la producción de la variedad local, el descenso del poder adquisitivo del pueblo debido a la depresión comercial y al alza de los derechos de importación del arroz. En este último aspecto el Gobierno ha logrado sus propósitos de intensificar el cultivo local.

Siam, de donde venía el 95 porciento del arroz importadoy Vietnam que proveía el resto, ambos vía Alemania, se perjudicaron al perder un mercado para su producto, que desde 1936 sólo se podía importar con permiso del gobierno. Por primera vez ese año la producción local excedió el volumen importado. La producción siguió creciendo y según datos de la Oficina Nacional de Estadisticas, en 1940 ésta fue de cerca de 39 millones de kgs., la cual subió a 210 millones en 1970 y para 1979 había llegado a más de 376. A pesar de este aumento, un cultivo que pasó a ser importado en casi su totalidad a ser ex portado, no ha podido mantener su ritmo de crecimiento de acuerdo a la demanda nacional, teniendo que ser importado periódicamente.

\section{CONCLUSIONES}

Varios aspectos resaltan en este relato, bastante breve y panorámico. Un tema tan complejo no se puede tratar a profundidad en un artículo tan breve como éste, sobre todo cuando se intenta hacer un re cuento histórico. En consecuencia, este artículo no pretende más que 
presentar unas cuantas informaciones que sugieren un estudio más sistemático para una historia del desarrollo dominicano y la incidencia de la agricultura en éste.

Se ha resaltado la importancia que a través de la historia han dado los dominicanos a la creación de un sistema agrícola. Sin embargo, esto sólo se ha logrado parcialmente, y aún es incapaz de definir la sociedad dominicana como auténticamente agrícola. En gran parte esto se ha debido al tipo de estructura colonial que se formó principalmente al inicio del siglo XVII cuando la sociedad se definió como ganadera, convirtiéndose el hato en la característica más relevante de la sociedad y que predominó por varios siglos hasta casi finales del siglo XIX, aunque perdió su ímpetu económico, que siempre fue precario, a principios de ese siglo.

A finales del siglo $X I X$, después de un período republicano acci dentado, de inestabilidad politica que distrajo los recursos que pu= dieron haber sido destinados a este fin, se logró sentar las bases de un sistema agrícola, que aún perdura, con la introducción de nuevos cultivos como el azúcar, el cacao y el café, junto al tabaco, que por un tiempo fue el único comerciable de importancia, hasta que comenzó a declinar y su lugar fue ocupado por los nuevos cultivos.

Junto a estos coexistió una agricultura de subsistencia, la que, con el pasar del tiempo, se ha convertido en insuficiente para satisfacer el consumo nacional, creándose asi una crisis en la producción de alimentos que, a medida que pasa el tiempo, se hace más sería. La política de desarrollo agrícola puso más énfasis en cultivos de deman da en el mercado internacional y se preocupó menos en transformar eT conuco para que fuera una unidad de producción rentable y para que su pliera de bienes esenciales la población nacional. Esta orientación aún persiste. Una excepción, que debió ser ilustrativa, fue el arroz, que logró un desarrollo notable, a pesar de su insuficiencia actual.

La base agrícola creada en el siglo XIX, aunque mejorada en algunas instancias, y siempre de forma parcial, en este siglo, no ha su frido cambios cualitativos sustanciales, a pesar de que ha entrado en crisis, como es el caso del azúcar, a cuyas alzas y bajas periódicas, hay que agregar la amenaza de su extinción en breve plazo debido a la introducción de nuevas formas de producir el dulce más eficientemente, como sucede actualmente con el uso del maíz para estos fines.

En sintesis, la República Dominicana aún está por ser un país agrícola. Si queda alguna duda, sólo hay que recordar que es un país importador de alimentos de consumo humano directo e indirecto, al importar alimentos para producir alimentos. 
Abad, José Ramón,

1888 Reseña General Geográfico-Estadistica. Santo Domingo: Imprenta García Hermanos, 1888. Segunda Edición fascímil por el Banco Central, 1972.

Bishop, Crowford M. y Anyda Marchant,

1976 "La Literatura Juridica en la República Dominicana", EmeEme, Estudios Dominicanos, V (25): 81-46. Julio-agosto, 1976.

Bonó, Pedro Francisco,

1964 Papeles de Pedro F. Bons. Emilio Rodríguez Demorizi (ed.), Academia Dominicana de la Historia, Vol. XVII, Santo Domingo: Editora del Caribe, 1964.

Bryan, Patrick,

1978 "The Transition of Plantation Agriculture in the Dominican Republic", 1870-84, Journal of Caribbean History, (10-11): $82-105,1978$.

Castillo, Manuel María,

1964

"Mi Opinión", En: Papeles de Pedro F. Bon反, Emil io Rodríguez Demorizi (ed.), Academia Dominicana de la Historia, Vol. XVII, Santo Domingo: Editora del Caribe, 1964. pp. 403-406.

Chaynov, A. V.,

1975 Oeuvres Choisies de A. V. Chaynov, Johnson Reprint, S. R. Publishers, Mouton, citado por Basile Kerblay en "Chaynov and the Theory of Peasantry as a Specific Type of Economy", En: Peasants and Peasant Societies, Teodor Shanin (ed.) Har mondsworth, Middlesex, Inglaterra: Penguin Modern Sociology Readings, Penguin Books. pp. 150-160.

Dechamps, Enrique,

1974 La Repáblica Dominicana, Directorio y Guía General, Santo Do mingo: Sociedad Dominicana de Bibliófilos, Editora de Santō Domingo, 1974. Edición Fascímil de la primera publicada en Santigo, 1907.

Dominican Customs Receivership,

1910 Foreign Aggregate Thade of the Dominican Republic, Calendar year 1909 .

1911 Summary of Commerce of the Dominican Republic, Calendar year 1910. 
Dominican Customs Receivership,

1913 Summary of Commerce of the Dominican Republic, Calendar year 1911.

1915 Summary of Commerce of the Dominican Republic, Calendar year 1913.

1923 Report of the Fifteenth Fiscal Period.

$$
\text { Report of the Twenty-Ninth Fiscal Period. }
$$

Dumont, René,

"Agriculture as Man's Transformation of the Rural Environment", En: Peasants and Peasant Societies, Teodor Shan in (ed.), Inglaterra: Penguin Modern Sociology Readings, Penguin Books. pp. 141-149.

Foster, George,

1967 "What is a Peasant", En: Peasant Society, A Reader, Jack M. Potter, et. al. (eds.), Boston: Little, Brown and Company, 1967.

Galeski, Boguslaw,

1975

"Social Organization and Rural Social Change", En: Peasants and Peasant Societies, Teodor Shan in (ed.), Inglaterra: Pen guin Modern Sociology Readings, Penguin Books, 1975. pp.115140.

Hazard, Samue 1,

1974

Santo Domingo, Past and Present with a Glance at Hayti, Samp son, Low, Marston, Low and Searle, 1873. Segunda edición fascímil en inglés y edición en español traducida por la So ciedad Dominicana de Bibliófilos, Santo Domingo: Editora de Santo Domingo, 1974.

Hostos, Eugenio María,

1939

Hostos en Santo Domingo, Emilio Rodríguez Demorizi (ed.).

Ciudad Trujillo: Imprenta J. R. Vda. García, Sucs., 1939.

Hunter, Guy,

1969-

Modernizing Peasant Societies, New York: Oxford University Press, New York, 1969.

Lamb, Ursula,

1977 Frey Nicolás de Ovando, Gobernador de las Indias, Santo Domingo: Sociedad Dominicana de Bibliófilos, Editora de Santo Domingo, 1977. 
Luperón, Gregorio,

1974 Notas Autobiográficas y Apuntes Historicos. Tercera edición fascimil, Santo Domingo: Sociedad Dominicana de Biblió filos, Editora de Santo Domingo, 1974.

Morse, Richard,

1973 Las Ciudades Latinoamericanas, Sep-Setentas. México: Di rección General de Educación Audiovisual y Divulgación, 1973.

Moya Pons, Frank,

1974 Historia Colonial de Santo Domingo. Santiago: Universidad Catól ica Madre y Maestra, 1974.

Oficina Nacional de Estadística,

1980a Producción Agrícola de Tabaco en Rama, 1936-1979.

1980b Producción Agrícola de Cacao, 1936-1979.

1980c Producción Agrícola de Cafe, 1936-1979.

1980d Producción Agrícola de Arroz, 1936-1979.

Pearse, Andrew,

1970 "Agrarian Change Trends in Latin America". En: Agrarian Problems and Peasant Movements in Latin America. Rodolfo Stavenhagen (ed.), Garden City, N. Y.: Anchor Books, Double day, 1970 .

Silié, Rubén,

1976 Economía, Esclavitud y Población, Ensayos de Interpretación Histórica del Santo Domingo Español en el Siglo XVIII, Colección Historia y Sociedad No. 20. Santo Domingo: Universidad Autónoma de Santo Domingo, 1976.

Tannenbaum, Frank,

1962 Ten Keys to Latin America. New York: Vintage Book, Division of Random House, 1962.

Tejera, Emiliano,

1941 a "Asuntos Económicos", Clío IX (49-50): 190-194. Septiembrediciembre, 1941.

1941b "Carta de U1 ises Heureaux", Clío IX(49-50): 194-195.

Thorner, Daniel,

1975 "Peasant Economy as a Category in Economic History". En: Peasants and Peasant Societies, Teodor Shanin (ed.), Inglate rra: Penguin Modern Sociology Readings, Penguin Books, 1975. 
Welles, Summer,

1973 La Viña de Naboth, Santo Domingo: Editora Taller, 1973.

Wolf, Eric,

1975 "Aspects of Groups Relations in a Complex Society": México: En: Peasants and Peasant Societies, Teodor Shanin (ed.). In glaterra: Penguin Modern Sociology Readings, Penguin Books, 1975. 